\title{
Information or Context: What Accounts for Positional Proximity between the European Commission and Lobbyists?
}

Patrick Bernhagen (corresponding author)

Andreas Dür

David Marshall

\begin{abstract}
Why are legislative proposals closer to the positions of some organized interests than of others? The literature proposes that policy-makers are attentive to the demands of lobbyists that provide relevant information. At the same time, being part of a policy community is also claimed to enable lobbyists to shape policy formulation. We argue that both factors reinforce each other: Informational resources are particularly effective in reducing the gap between the Commission's policy position and the position of lobbyists if both actors are part of the same policy community. Analysing data on over 100 policy issues in the European Union, we find that the context of a friendly Directorate-General reinforces the effectiveness of lobbyists' informational resources. However, on its own, a context of friendly relations between the policy-maker and the lobbyist contributes little to explaining why the European Commission's policy position is closer to some actors than to others.
\end{abstract}

Keywords: lobbying; institutional context; policy communities; information; spatial analysis; EU Commission

\section{Acknowledgements:}

We thank Dominic Pakull for research assistance and Joost Berkhout, Jan Beyers, Caelesta Braun and Heike Klüver for helpful comments on earlier versions of this article. Without the many respondents in the European Commission that were willing to be interviewed this research would not 
have been possible. We also acknowledge financial support from the Austrian Science Fund (FWF), project number I 576-G16. This research is part of the INTEREURO project (www.intereuro.eu). 
The political success of organized interests is widely considered to depend on their capacity to provide helpful information: Lobbyists that can offer high-quality information to policy-makers should be most successful in gaining access and shaping policy outcomes (Ainsworth 1993; AustenSmith 1993; Lohmann 1993). At the same time, favourable context conditions, such as a policy community encompassing the policy-maker and lobbyist, are seen as a prerequisite for successful lobbying (Knoke et al. 1996; Marsh 1998; Vogel 1989). Interest groups that face policy-makers who are favourably predisposed to them will find it easier to exert influence (Richardson and Jordan 1979; Marsh 1998, Marshall 2010). Yet to date, the relationship between informational factors and context conditions remains unclear: What is the relative importance of these two factors in interest group politics? And how, if at all, do they interact in shaping the extent to which groups can achieve their desired policy outcomes?

We argue that the ability to provide relevant information (i.e. information that can help a policymaker assess the likely consequences of a planned policy change) is the primary factor explaining how close legislative proposals are to the policy positions of lobbyists. However, we also contend that the effectiveness of lobbyists' informational capacities is affected by the institutional context: the ability to offer relevant information may be ineffective if a group faces hostile political decisionmakers. Facing friendly policy-makers, in turn, should help those interest groups that can offer relevant information. It is therefore important to analyse how the combination of information and context accounts for the ability of interest groups to shape policy formulation.

To investigate this question we focus on the distance between the policy positions of organized interests and the European Commission at the policy formulation stage of the EU legislative process. It is widely recognized that lobbyists are well advised to get involved before a policy gets to the stage of public controversy (Dunleavy 1991) or becomes subject to plenary parliamentary debates (Austen-Smith 1993; Schlozman and Tierney 1986) and ideally even before specific policy 
instruments and documents are formulated (Baumgartner and Leech 1998; Bouwen 2009: 25-6). Indeed, the degree of positional proximity has major implications for the output of the European policy process: Lobbyists who manage to shape policy early on find their preferences much better reflected in the resulting legislation (Dür et al. 2015). However, existing analyses of lobbying tend to focus on the decision-making stage of the policy process. Only recently have scholars begun to investigate systematically the role of organized interests at the policy formulation stage of the EU policy process (Bunea 2013; Klüver 2013).

In the following sections, we first develop a theoretical account of the role of information and institutional context in early stage lobbying in the EU and derive hypotheses. We then introduce the data used for testing these hypotheses before proceeding to present our findings. These data capture lobbying on over 100 policy issues in the EU. We conclude by relating our results to the literatures on lobbying and on public policymaking in the EU.

\section{EXPLAINING POSITIONAL PROXIMITY BETWEEN POLICY-MAKERS AND}

\section{LOBBYISTS}

Lobbying is most effective when applied at the policy formulation stage (Austen-Smith 1993; (Dunleavy 1991; Bouwen 2009). In the EU, policy formulation is mainly the task of the European Commission. The Commission is the main agenda setter for the EU's legislative activity and it has the prerogative of initiating and drafting legislative proposals. The political preferences of interest groups can enter the Commission's proposals in two ways: The Commission can listen to the lobbyists that possess a high level of policy-relevant knowledge, or it can listen to the groups with whom it shares broader political beliefs irrespective of their knowledge levels. We call these the informational argument and the context argument. In the following, we first develop these two expectations and then describe how the two factors reinforce each other. 
The information argument starts with the assumption that political lobbying consists primarily in transmitting information to policy-makers. Policy-makers need the information that societal groups provide to translate their political goals effectively into outcomes (Austen-Smith 1993; Ainsworth 1993; Lohmann 1993). Importantly, information and expertise enable organized interests to shape policy-makers' beliefs about which of various policy choices would lead to desired outcomes and which would not - or even have unwanted and harmful consequences. The European Commission has an additional reason to listen to interest groups that possess high-quality information. Like other agenda setting agencies, it seeks to formulate policy proposals that will successfully pass the subsequent legislative process (Romer and Rosenthal 1978; Tsebelis and Garrett 2000; Moravcsik 1999). For its policy proposals to become legislation, they have to be approved by the Council of Ministers and the European Parliament (EP). In order to produce such policies, the Commission needs policy-relevant information from societal actors represented by national and European-level interest organizations (Crombez 2002; Klüver 2013). The Commission therefore consults with interest groups to maximize the subsequent success of its policy proposals (Bouwen 2002; Klüver 2013; McLaughlin, Jordan and Maloney 1993).

When there is conflict among groups over policy, the Commission's draft proposals will be closer to the political position of some interest groups than of others. In the process of policy formulation, the policy proposal represents the Commission's policy position (which may or may not be identical with its preferences). Because of the two reasons presented above, the informational argument suggests that, in such cases, the Commission's policy proposals resemble an interest group's position more closely the more relevant information the group can bring to the consultation and lobbying process. Thus, we expect that

H1a: The distance between a lobbyist's position and the Commission position decreases with the level of relevant information the lobbyist commands. 
In the EU as elsewhere, much lobbying is embedded in coalitions of actors sharing positions and pursuing common political goals. These may be coalitions based on formal organizational ties (Mizruchi and König 1991; Hula 1999), ad hoc coalitions involving a degree of coordination (Pijnenburg 1998) or simply 'sides' of lobbyists, defined as a subset of actors who share the same policy goal (Baumgartner et al. 2009; Heinz et al. 1993; Klüver 2013). ${ }^{1}$ For our analysis it is important to take these sides of actors into account: Actors availing of little or poor information may find the distance between the Commission's position and their own reduced because another actor on the same side can offer relevant information to the Commission. Thus, we should expect that information provided by issue-specific sides of lobbyists pulling the policy-maker in the same direction accounts for some of the variation in proximity between the Commission and an individual lobbyist. To incorporate this dimension into our analysis, we define 'side' as a group of lobbyists holding similar or close positions on a specific issue. According to these considerations, we expect that

H1b: The distance between a lobbyist's position and the Commission position decreases with the level of relevant information the lobbyist's side commands.

The extent to which policy-makers respond to lobbying may also depend on the institutional context (Dür and De Bièvre 2007). The context argument starts with the insight that different policymaking venues are more favourable to some organized interests than to others and that groups adjust their strategies accordingly (Baumgartner and Jones 1993). In the case of EU policy formulation, regular interactions are maintained between specific interest groups and the Directorates-General (DGs) dealing with policies affecting these groups. This happens for two reasons: Firstly, because organized interests attempt to seek out the most relevant policy-makers for the pursuit of their political 
interests, and secondly, because the Commission seeks contact with selected organized interests in its search for policy information and legitimacy (cf. Bouwen 2002).

As a result, policy communities have formed around individual DGs (Dudley and Richardson 1999; Peterson 1995, Coen 2007). Business interests are more likely to maintain contacts with DG Enterprise and Industry while DG Environment is more likely to liaise with environmental groups (Bouwen 2009, 24). Consequently, while DGs and their staff may pursue their own preferences concerning policy, they are also imbedded in policy communities that include interest groups. DGs therefore constitute important institutional factors that must be taken into account when analyzing lobbying and policy-making (cf. Klüver et al. 2014 in this special issue). These communities involve a limited number of participants that share similar ideologies and values and engage in frequent and high quality interaction (cf. Richardson and Jordan 1979). Thus, when policy-makers look for input when formulating policies, they are likely to give particular attention to lobbyists who share their broader political outlook and belief system (Sabatier and Jenkins-Smith 1993). Lobbyists, in turn, can be thought of as dealing with a friendly policy-maker. As in many political systems, including the EU, policy formulation frequently involves cooperation across different policy units under the lead of one. But it is the relationships with the department leading the policy formulation task that usually matter most. Thus, we hypothesize that

H2a: The distance between a lobbyist's position and the Commission position is smaller if the lobbyist faces a friendly lead DG.

Once again, we expect to make a similar observation if the side of the lobbyist is dealing with a friendly DG. 
H2b: The distance between a lobbyist's position and the Commission position is smaller if the lobbyist's side faces a friendly lead DG.

So far we have discussed separately how the proximity of policy positions between lobbyists and the policy-maker is affected by lobbyist's information resources and by their relationship with the policy-maker. But the extent to which the policy process is shaped by information asymmetries between organized interests and policy-makers is itself likely to vary with the institutional context. The reason for this is that the quality and utility of information provided by interest groups can only be assessed retrospectively. Hansen (1991) has demonstrated that this leads policy-makers to restrict access to those groups with whom they expect to have repeated interactions in the future. In the EU's system of 'élite pluralism' (Coen 1997), numerous points of access to the policy process mean that policy-makers are exposed to different lobby messages from numerous sources. Yet, while policymakers may thus listen to different actors they will be careful when using the received information in policy formulation. EU Commission staff should rely more heavily on information received from lobbyists sharing their broader political beliefs relative to information provided by other lobbyists. Therefore, we extend the logic underpinning Hansen's argument to contend that policy-makers' restricted capacity to verify the utility of information supplied by lobbyists also constrains the extent to which the information that is received is put to use. In other words, the policy-maker's information problems bias not only their openness to information supplied by established actors but also the extent to which they translate received information into policy.

In the EU, DGs form closer relationships with interest organizations that provide relevant and reliable information over time (Coen and Katsaitis 2013; Broscheid and Coen 2003). This implies that organized interests are better positioned to bring their information and expertise to bear on the formulation of policy proposals when interacting with 'friendly' agenda setters. As a result, relevant information held by organized interests is more effective in bringing the Commission position closer 
to the lobbyist's position if the group in question is dealing with a friendly DG. At the same time, lobbyists might find that the information they provide is used more explicitly or openly by the Commission DG because their position is close to that of the DG. As Boswell (2008) suggests, there might be an instrumental use of policy knowledge within the Commission, with policy-makers selectively drawing from the pool of expertise in order to legitimize or validate their existing policy positions. Similarly, Broscheid and Coen (2003) and Coen and Katsaitis (2013) have argued that EU policy-makers encourage access from groups they perceive to provide the type of information that helps to legitimize the policy they favour already. Once again, this logic might apply to sides of lobbyists as much as to individual actors. Thus, we expect that

H3a: Increases in the lobbyist's information level reduce the distance between the lobbyist's position and the Commission position if the lobbyist faces a friendly lead DG.

And

H3b: Increases in the lobbyist's information level reduce the distance between the lobbyist's position and the Commission position if the lobbyist's side faces a friendly lead DG.

\section{DATA, MEASUREMENT AND ESTIMATION STRATEGY}

To evaluate the theoretical claims formulated in the previous section, we employ several approaches to data collection. The starting point for the analysis is the INTEREURO random sample of 125 legislative proposals, adopted by the European Commission between $1^{\text {st }}$ January 2008 and $31^{\text {st }}$ December $2010 .^{2}$ This period was selected to be both recent enough for interviewees to be accessible, while increasing the chances that at the time of the interview the legislative process would have concluded. The sample is confined to regulations and directives as they share a number of decision-making features that allow meaningful comparisons across proposals. This consideration 
necessitated separate sampling, as a simple random approach would have led to the inclusion of very few directives. To reduce the likelihood of capturing purely administrative cases or too many on which lobbying activity was highly unlikely, the sample was quantified to contain a minimum amount of publically salient issues. Salience is operationalized as media coverage in at least two of five leading pan-European and national newspapers: Agence Europe, European Voice, the Financial Times, the Frankfurter Allgemeine Zeitung, and Le Monde. ${ }^{3}$

As the focus of interest group representation at the consultation stage, the Commission is uniquely placed to provide information on the range of actors playing a prominent role in the policy process. On the basis of the sample, interviews were conducted with Commission officials that had direct responsibility for preparing a proposal from its consultation phase onwards. The initial step was to identify the lead DG via the Prelex database and from there track down the current whereabouts of the official in question. Information was provided for 70 legislative proposals (44 directives and 26 regulations), which between them represent the theoretically important variation of the sample. ${ }^{4}$ Following the approach pioneered by Thomson et al. (2006), the relevant Commission expert for each proposal was asked to identify the unidimensional issue(s) that had attracted controversy between stakeholders. ${ }^{5}$ This is a necessary step to establish actor positions as well as to make meaningful comparisons between issues. In total, the respondents identified 112 issues, with the distribution ranging from one to four issues per proposal. There is no evidence to suggest that officials misrepresent issues, but we nevertheless undertook steps to validate their recollections. This involved locating all available interest group consultation submissions. Two researchers identified and recorded all policy issues; afterwards they compared their findings with the issues identified by the Commission officials. A third coder resolved the 16 disparities. In total 173 documents were analysed, encompassing 31 proposals (44 per cent of sample), enabling us to assess the validity of 50 of the 112 identified issues. The result was encouraging: 49 (98\%) of the policy issues identified in the interviews were also prominent within the written submissions. 
Through the Commission interviews, we were able to establish for each issue a list of the more prominent and active organized interests. In total, 1,043 non-state advocates were identified, with a mean of 9.8 actors per issue. ${ }^{6}$ There was considerable variation across the 16 DGs, with the number of groups ranging from 4 to $321 .^{7}$ The officials then estimated the relative policy positions for each interest group that they identified as active on a given issue, as well as for institutional actors including the Council, EP majorities, and the Commission. These were placed along a unidimensional issue continuum with a range of 0-100, where zero means least support for EU regulation and higher values indicate support for more regulation.

The dependent variable is distance to the Commission. This is an absolute measure of the distance between a lobbyist's ideal policy position and that of the Commission. It is derived from the positional data of actors placed along each of the 112 issue continua. The variable has a trimodal distribution, with a large number of values around 0,50 and $100{ }^{8}$ This reflects the fact that the Commission often adopts positions at these values (in 12 percent of the cases a position between 0 and 5; in 16 percent between 45 and 55; and in 30 percent between 95 and 100). In Figure 1, we show the average distance to the Commission per DG with primary responsibility. The distance clearly varies across DGs, with some (e.g. DG Justice, Freedom \& Security) positioned much more closely to interest groups than others (e.g. DG Trade). To assess the validity of the Commission officials' positional estimates, we made a further comparison with the consultation documents. To minimize coding error, given the complexity of the narratives, the issue continuum was simplified to a three-point scale $(0,50,100)$. Two researchers located and compared 263 policy positions found within a corresponding set of 173 written submissions. The level of agreement between the official's recollection and the positions expressed in the consultation documents was high, with a Krippendorff's alpha of 0.88 [CI: $0.84,0.94]$ providing considerable confidence in the officials' estimates. 
[Insert Figure 1 about here]

To gauge the extent to which organized interests command relevant policy information, each Commission official was asked to assess 'the level of technical knowledge each organisation holds with respect to this policy proposal'. Using a five-point scale, with ' 0 ' indicating very low and ' 4 ' very high, levels of policy-relevant knowledge (IG knowledge) were estimated by the Commission official for 939 groups. 45 percent of all actors in our dataset were coded 4 on this variable, 24 percent were coded 3 and 31 percent were coded 2 or lower. We have confidence in the Commission's estimates, particularly given the encouraging results from the aforementioned comparisons with exogenous information sources. In the analysis below, we use this variable, firstly, at the level of individual interest group and, secondly, as an aggregate knowledge measure for each side on an issue. To arrive at the side variable, we assign each side of an issue the maximum value on IG knowledge estimated for a member of that side (IG knowledge (side)). In other words, a lobbying side is assumed to claim the knowledge of its best informed member. We identify sides as all actors that are within a range of $+/-10$ points on the issue continuum that ranges from $0-100$. To illustrate, the side of an actor located at 20 encompasses all actors with a position between 10 and 30 . We chose this operationalization of sides to avoid fixed cut-off points along the issue continuum creating artificial breaks. For example, opting for two sides, one to the left and the other to the right of 50, would mean that an actor located at 49 forms part of the same side as an actor at 0 ; but finds herself on opposite sides to an actor at 51.

The classification of the relationship between types of organised interest and each of the 16 DGs as friendly or unfriendly proved to be remarkably clear cut, in particular to those involved in EU policy making. Hence there was full coding agreement amongst a panel of five experienced EU officials 
(outside of the Commission) and academic researchers. From these expert categorisations we created a dummy variable Friendly $D G$ that is coded 1 if the lobbyist is:

a. a business actor and the lead DG is Trade, Energy \& Transport, Internal Market \& Services, Economic \& Financial Affairs, Enterprise \& Industry, or Taxation \& Customs Union;

b. an environmental group and the lead DG is Environment;

c. a health or consumer group and the lead DG is Health \& Consumer Protection;

d. a labour union and the lead DG is Employment, Social Affairs \& Equal Opportunities;

e. an agricultural association and the lead DG is Agriculture \& Rural Development; or

f. a fisheries association and the lead DG is Maritime Affairs \& Fisheries.

All other group-DG dyads are coded ' 0 '. Applying these rules, 570 groups were coded 0; 473 groups were coded $1 .{ }^{9}$ We also calculated a 'Friendly DG' variable for each side of lobbyists. We do so by calculating the share of actors on one side that faces a friendly DG (friendly DG (side)). ${ }^{10}$ Summary statistics for all variables are provided in Table A-1 in the online appendix.

To approximate the ceteris paribus condition, the multivariate analysis that follows uses a number of control variables. We include a nominal variable - regulation - to capture the use of this legal instrument in contrast to directives. To take account of the possible effect that the sheer number of actors aligning with any one particular actor may have on the results, we control for the size of lobbying side, where sides are defined as above. Furthermore, it is possible that high levels of public attention may diminish the advantage of lobbying 'friendly' policy-makers (Schattschneider 1960; Danielian and Page 1994). Therefore, we control for the possible effects of media attention by counting the number of times each of the 70 proposals is mentioned across the five aforementioned media sources. As the effect of media attention should be marginally decreasing, we use the natural $\log$ of that number. The institutional context is highly correlated with group type: 88 per cent of the 
actors that are coded as facing a friendly DG are firms or business associations. ${ }^{11}$ This variable may therefore capture the effect of group type as much as, or more than, the friendliness of DGs, a possibility that is also suggested by recent evidence that business interests tend to be less successful in shaping EU legislation than non-business actors (Dür et al. 2015). We control for group type using a dummy variable that is coded 1 for business interests and 0 for other types (business).

We estimate a linear model with random intercepts at the proposal and issue levels. The random intercepts account for the nested nature of the observations: several actors lobby on the same issue, which are in turn bundled within proposals. This enables us to control for any remaining but unobserved issue and proposal-level factors shaping policy actors' success. Because of missing values for some covariates, the number of observations varies slightly across models.

\section{RESULTS}

To assess these expectations, we first estimate a model containing all covariates, but no interaction terms (Model 1 in Table 1). According to Hypothesis 1a we expect the distance between an actor's position and the position of the lead DG to be smaller, the more information the actor has about an issue. The coefficient for IG knowledge is indeed negative and statistically significant. Hypothesis $2 \mathrm{a}$ states that actors facing a friendly DG should be closer to the Commission position than other actors. Model 1 does not support this expectation: the coefficient for friendly DG is not statistically different from zero. Of the control variables, the coefficient for regulation is positive and weakly statistically significant. On regulations, interest groups find themselves further away from the Commission position than on directives. The positive and strongly statistically significant coefficient for side is unexpected, as a larger number of actors on a side is associated with greater distance from the Commission position. ${ }^{12}$ The amount of media attention is not associated with lobbyists' distance to the Commission. By contrast, the coefficient for business is positive and statistically significant, confirming previous research reporting a lack of business success in the EU (Dür et al. 2015). 
[Insert Table 1 about here]

In Model 2 (Table 1) we analyse 'lobbying as a collective enterprise' (Klüver 2013b) using the lobbying side variables outlined above (IG knowledge (side) and friendly DG (side)). In this model, the coefficient for IG knowledge (side) is negative and statistically significant. As a side's knowledge score increases by one point, an actor within that side can expect to be more than seven points closer to the Commission. Model 2 thus supports Hypothesis 1b. However, analogous to the analysis of individual actors' relationship with the Commission's policy units, we do not find support for Hypothesis 2b: a greater share of actors facing a friendly DG does not move the Commission closer to that side. The coefficients for the control variables are very similar to those that we estimated in Model 1. So far, the evidence supports Hypothesis $1 \mathrm{a}$ and $1 \mathrm{~b}$ but fails to back Hypotheses $2 \mathrm{a}$ or $2 \mathrm{~b}$.

In Model 3, we investigate the interaction between IG knowledge and friendly DG. Hypothesis 3a states that relevant knowledge is particularly useful to actors facing a friendly DG. As expected, the coefficient for the interaction term is negative and statistically significant. Knowledge is not statistically significant in this model (because of the interaction term, this is the effect of knowledge when a group does not face a friendly DG), and facing a friendly DG is associated with a larger distance between the lobbyist and the Commission (which is the effect when IG knowledge is zero). To facilitate interpretation, Figure 2 shows graphically how the effect of IG knowledge on distance is conditional on the institutional context: while actors that face a friendly DG benefit from increased informational capacities, actors lobbying a non-friendly DG do not. Surprisingly, at low levels of information capabilities, the Commission is closer to non-friendly interest groups than to friendly groups (the effect is weakly statistically significant). For actors with excellent information capabilities, those facing a friendly DG find themselves closer to the Commission's position than 
those facing a non-friendly DG, but the difference between the two groups is not statistically significant. Thus, the evidence so far entails partial backing for Hypothesis 3a.

[Insert Figure 2 about here]

In Model 4 we include an interaction term for IG knowledge (side) and friendly DG (side) to test Hypothesis 3b. Similar to Model 3, the coefficient for this term is negative and statistically highly significant. Figure 3 shows this effect graphically. While friendly $D G$ (side) is a continuous variable, we only show the results for instances in which this variable takes its extreme values ( 0 and 100$)$, that is, when either no group on a side faces a friendly DG or all actors on that side face a friendly DG. Actors whose sides face a friendly DG strongly benefit from more information. While for actors that do not face a friendly DG the line of prediction also has a slightly negative slope, the coefficient is very small and not significant. Again, however, the fact that at low levels of information capability, the Commission's position is further away from actors whose side faces a friendly DG than from actors whose side faces a non-friendly DG is puzzling. Model 4 thus supports the expectation that knowledge matters more when applied in a friendly institutional context, but it still offers only partial backing for Hypothesis $3 b$.

[Insert Figure 3 about here]

Overall, we find that the ability to provide technical knowledge is effective in narrowing the gap between the policy positons of the lobbyist and the policy-maker (Hypotheses 1a and 1b). By contrast, friendly relations between a lobbyist (the lobbyist's side) and a policy-maker do not matter for the position that the policy-maker adopts on an issue (Hypotheses $2 \mathrm{a}$ and $2 \mathrm{~b}$ ). We also find that the effect of information is moderated by the relationship between interest groups and a policymaker. Information only matters for groups facing a friendly policy-maker (Hypotheses $3 \mathrm{a}$ and $3 \mathrm{~b}$ ). 
In operationalizing our research problem we made several decisions about measurement and estimation strategy that might affect our findings. To check whether they do, we conduct further robustness analyses in which we estimate similar models as those reported in Table 1 but apply alternative measurement and estimation options. In Models 2 and 4 of Table 1, we operationalized IG knowledge (side) by taking the maximum value for IG knowledge observed for each side. However, it is possible that the Commission actually listens to the side that provides the best information on average. We take account of this possibility by calculating an alternative IG knowledge (side) variable that takes the mean on IG knowledge for each side. Using this variable instead of the one used in Models 2 and 4 does not affect our results. Neither does operationalizing sides with fixed cutoff points (0-20, 21-79, and 80-100) change our substantive findings. Full details are reported in Table A-2 in the online appendix.

Furthermore, we assess whether our results are robust to changes in estimation strategy. While we have so far relied on linear regression with random intercepts, this estimator tends to discount the large number of $0 \mathrm{~s}$ and $100 \mathrm{~s}$ in our dependent variable. To see whether our results are sensitive to the approach to analyzing the data, we convert the dependent variable into an ordinal variable taking on the values 0 (distance from 0 to 10 ), 1 (distance greater than 10 but smaller than 60 ) and 2 (distance 60 or larger) and estimate the models using ordinal logistic regression (Table A-3). As before, these models include random intercepts at the proposal and issue levels. The results fully support the substantive findings reported above.

\section{CONCLUSIONS}

Following informational theories of lobbying (Ainsworth 1993; Austen-Smith 1993; Lohmann 1993), we have argued in this article that the positions of policy-makers should be closer to those of lobbyists (or sides of lobbyists) that avail of large amounts of policy-relevant information. Taking 
into account insights from research on policy communities (Richardson and Jordan 1979; Marsh 1998) and advocacy coalitions (Sabatier and Jenkins-Smith 1993), we also expected policy-makers to be closer to lobbyists (or sides of lobbyists) with whom they entertain friendly relations and share common beliefs. Finally, we combined the two arguments by proposing that the effect of policyrelevant information is particularly effective if the relationship between the policy-maker and the lobbyist (or side of lobbyists) is situated in a friendly institutional context.

Examining these expectations using data on policy formulation and lobbying in the EU, we found support for the argument that the amount of relevant knowledge a lobbyist or her side is able to bring to the policy process accounts for some of the proximity of positions between the European Commission and lobbyists. By contrast, the presence of a friendly institutional context on its own does not have an impact on the policies that the agenda setter formulates. Rather, our analysis suggests that the institutional context moderates the effect of informational resources: information matters for groups facing a friendly DG. Overall, therefore, the evidence presented in this paper backs informational theories of lobbying, while lending only qualified support to theories emphasizing the contextual nature of policy formulation. At the same time, the fact that context moderates the effect of information suggests that who you know might only be important inasmuch as it provides a lobbyist with the opportunity for applying what you know in the policy process. Bringing knowledge to bear on policy formulation is facilitated by favourable contexts. The effect of policy-relevant technical knowledge under these circumstances is that the positions of the policymaker and the lobbyist are closer to one another than they would otherwise be. In this sense, the data tell us which lobbyists are more successful in the context of early stage lobbying than others: those with high levels of relevant knowledge who also enjoy favourable relationships with the Commission's policy units. 
An unexpected finding of this research is the fact that, at low levels of lobbyists' informational resources, the Commission's position is further away from actors whose side faces a friendly DG than from actors whose side faces a non-friendly DG. This suggests that the Commission discounts lobbying by actors sharing its political beliefs while accommodating others. While exploring the reasons for this is beyond the scope of the present article, it may be possible that Commission staff discount the positions of lobbyists within their policy community to avoid the impression of catering to their friends' interests. As a result, the Commission formulates policy proposals which friendly interest organisations support only if these organisations provide high quality information.

Alternatively, groups that have a friendly relationship with the Commission may not bother to become active on a Commission proposal that is close to their preferences. This would imply that we have overestimated the average distance between the Commission and friendly groups. Future research should probe further into these lines of inquiry.

We close on a note of caution: We have developed and tested arguments explaining the positional proximity between lobbyists and policy-makers. However, the successful early-stage lobbyists in our analysis were not necessarily influential in shaping the Commission's policy position: Proximity per se does not necessarily imply 'influence'. Influential actors are able to place their preferred policy proposals on the official agenda while averting proposals that they dislike, and the prevalence of these proposals depends on the actions or some properties of the influential actor. In the research presented here, we cannot rule out that lobbyists find their positions closely matched by the policymaker due to 'luck' rather than influence (cf. Barry, 1980). However, while individual policy actors might occasionally be lucky, if luck was all that matters we should not observe statistically significant associations between positional proximity and the variables that, as we have argued, serve to explain some of this proximity. Moreover, it is possible that knowledgeable lobbyists benefit from friendly DGs because these DGs aim to bolster the case for their policy positions with information supplied by the respective lobbyists or because they seek to envelop their policy proposals in claims 
of legitimacy based on consultations with relevant organized interests. Future research should aim to disentangle the strategic behaviour and causal relationships underlying these observationally equivalent interpretations.

\section{REFERENCES}

Ainsworth, S. (1993) 'Regulating lobbyists and interest group influence. Journal of Politics 55(1): 41-56.

Austen-Smith, D. (1993) 'Information and influence: Lobbying for agendas and votes', American Journal of Political Science 37(3): 799-833.

Barry, B. (1980) 'Is it better to be powerful or lucky?: part 1', Political Studies 28(2): 183-194.

Baumgartner, F.R. and Jones, B.D. (1993) Agendas and Instability in American Politics. Chicago: University of Chicago Press.

Baumgartner, F.R. and Leech, B. (1998) Basic Interests: The Importance of Groups in Politics and in Political Science, Princeton: Princeton University Press.

Baumgartner, F.R. et al. (2009) Lobbying and Policy Change: Who Wins, Who Loses, and Why, Chicago: University of Chicago Press.

Beyers, J., Braun, C., Marshall, D. and De Bruycker, I. (2014c) 'Let's talk! On the practice and method of interviewing policy experts', Interest Groups \& Advocacy 3(2), 174-187.

Beyers, J., Dür A., Marshall, D., Wonka, A. (2014b) 'Policy-centred sampling in interest group research: lessons from the INTEREURO project', Interest Groups \& Advocacy, 3(2), 160173.

Beyers, J., Chaques Bonafont, L., Dür, A., Eising, R., Fink-Hafner, D., Lowery, D., Mahoney, Ch., Maloney, W. \& Naurin, D. (2014a) 'The INTEREURO Project: Logic and Structure', Interest Groups \& Advocacy, 3(2), 126-140.

Boswell, C. (2008) 'The Political Functions of Expert Knowledge: Knowledge and Legitimation in European Union Immigration Policy', Journal of European Public Policy 15(4): 471-488. 
Bouwen, P. (2002). Corporate lobbying in the European Union: The logic of access. Journal of European Public Policy 9(3): 365-390.

Bouwen, P. (2009) The European Commission, in: David Coen and Jeremy Richardson (eds) Lobbying the European Union: Institutions, Actors, and Issues. Oxford: Oxford University Press, 212-32.

Broscheid, A. and Coen, D. (2003) 'Insider and outsider lobbying of the European Commission: an informational model of forum politics', European Union Politics 4(2): 165-91.

Bunea, A. (2013) 'Issues, preferences and ties: determinants of interest groups' preference attainment in the EU environmental policy', Journal of European Public Policy 20(4): p.552-70.

Coen, D. (2007) 'Empirical and Theoretical Studies on EU Lobbying', Journal of European Public Policy, 14(3): 333-345.

Coen, D. (1997) 'The evolution of the large firm as a political actor in the European Union' Journal of European Public Policy 4(1), 91-108.

Coen, D., and Katsaitis, A. (2013) 'Chameleon pluralism in the EU: an empirical study of the European Commission interest group density and diversity across policy domains', Journal of European Public Policy, 20(8): 1104-1119.

Crombez, C. (2002) 'Information, Lobbying and the Legislative Process in the European Union', European Union Politics 3(1): 7-32.

Danielian, L.H. and Page, B.I. (1994) 'the heavenly chorus: Interest group voices on TV news', American Journal of Political Science 38(4): 1056-1078.

Dudley, G. and Richardson, J. (1999) 'Competing advocacy coalitions and the process of "frame reflection": a longitudinal analysis of EU steel policy', Journal of European Public Policy, 6(2): 225-248.

Dunleavy, P. (1991) Democracy, Bureaucracy and Public Choice. Hemel Hempstead: Harvester.

Dür, A. and De Bièvre, D. (2007) 'Inclusion without influence? NGOs in European trade policy.' Journal of Public Policy 27(1): 79-101. 
Dür, A., Bernhagen, P. and Marshall, D. (2015) 'Interest Group Success in the European Union: When (and Why) Does Business Lose?' Comparative Political Studies, forthcoming. Hansen, J.M. (1991) Gaining Access: Congress and the Farm Lobby, 1919-1981, Chicago: University of Chicago Press.

Heinz, J.P., Laumann, E.O., Nelson, R.L. and Salisbury, R.H. (1993) The Hollow Core: Private Interests in National Policy Making. Cambridge, MA: Harvard University Press.

Hula, K.W. (1999) Lobbying together: Interest group coalitions in legislative politics. Washington D.C.: Georgetown University Press.

Klüver, H. (2013) Lobbying in the European Union: Interest Groups, Lobbying Coalitions, and Policy Change, Oxford: Oxford University Press.

Klüver, H., Beyers, J. and Braun, C. (2014) <THIS ISSUE: PUBLISHER TO ADD /UPDATE DETAILS AT PROOF $>$ )

Knoke, D., Pappi, F.P., Broadbent, J. and Tsujinaka, Y. (1996) Comparing Policy Networks. Cambridge: Cambridge University Press.

Lohmann, S. (1993). ‘A signaling model of informative and manipulative political action', American Political Science Review 87(2): 319-333.

Marsh, D. (ed.) (1998) Comparing Policy Networks. Buckingham: Open University Press. Marshall, D. (2010) 'Who to Lobby and When: Institutional determinants of Interest Group Strategies in European Parliament Committees', European Union Politics 11(4): 553-575. McLaughlin, A.M., Jordan, G. and Maloney, W. (1993) 'Corporate Lobbying in the European Community', Journal of Common Market Studies 31(2): p.191-212.

Mizruchi, M.S., König, T. (1991) ‘Size, Concentration and Corporate Networks: Determinants of Business Collective Action', Social Science Quarterly, 72(2): 299-313.

Moravcsik, A. (1999) ‘A New Statecraft? Supranational Entrepreneurs and International Cooperation' International Organization 53(2): 267-306. 
Peterson, J. (1995) 'Decision-making in the European Union: Towards a framework for analysis', Journal of European Public Policy, 2(1): 69-93.

Pijnenburg, B. (1998) 'EU lobbying by ad hoc coalitions: an exploratory case study', Journal of European Public Policy, 5(2): 303-321.

Richardson, J.J. and Jordan, A.G. (1979) Governing under pressure the policy process in a postparliamentary democracy. Oxford: Robertson.

Romer, T., and Rosenthal, H. (1978) 'Political Resource Allocation, Controlled Agendas, and the Status Quo’ Public Choice 33(4): 27-43.

Roscoe, D. D. and Jenkins, S (2005) ‘A Meta-Analysis of Campaign Contributions' Impact on Roll Call Voting', Social Science Quarterly 86: 52-68.

Sabatier, P., and Jenkins-Smith, H. eds. (1993) Policy Change and Learning: An Advocacy Coalition Approach. Boulder: Westview Press.

Schattschneider, E.E. (1960) The Semisovereign People. New York: Holt, Rinehart, and Winston.

Schlozman, K. L. and Tierney, J.T. (1986) Organized Interests and American Democracy. New York: Harper and Row.

Thomson, R, Stokman, F. N., Achen, C., and Koenig, T. (eds.) (2006) The European Union Decides. Cambridge, UK: Cambridge University Press.

Tsebelis, G. and Garrett, G. (2000) 'Legislative Politics in the EU', European Union Politics 1(1): 936.

Vogel, D. (1989) Fluctuating Fortunes: The Political Power of Business in America. New York: Basic Books. 


\section{Author information}

Patrick Bernhagen is Professor of Comparative Politics at the University of Stuttgart

Address for correspondence: Institute of Social Sciences, University of Stuttgart, 70174 Stuttgart, Germany, email: patrick.bernhagen@sowi.uni-stuttgart.de

Andreas Dür is Andreas Dür is Professor of International Politics at the University of Salzburg

Address for correspondence: Department of Political Science, University of Salzburg, Rudolfskai 42, 5020 Salzburg, Austria, email: andreas.duer@sbg.ac.at

David Marshall is Research Fellow at the University of Aberdeen

Address for correspondence: Department of Politics and International Relations, University of Aberdeen, Edward Wright Building, Dunbar Street, Aberdeen, AB24 3QY, United Kingdom, email: dmarshall@abdn.ac.uk 
Figure 1: Positional distance between Commission and lobbyist, by DG

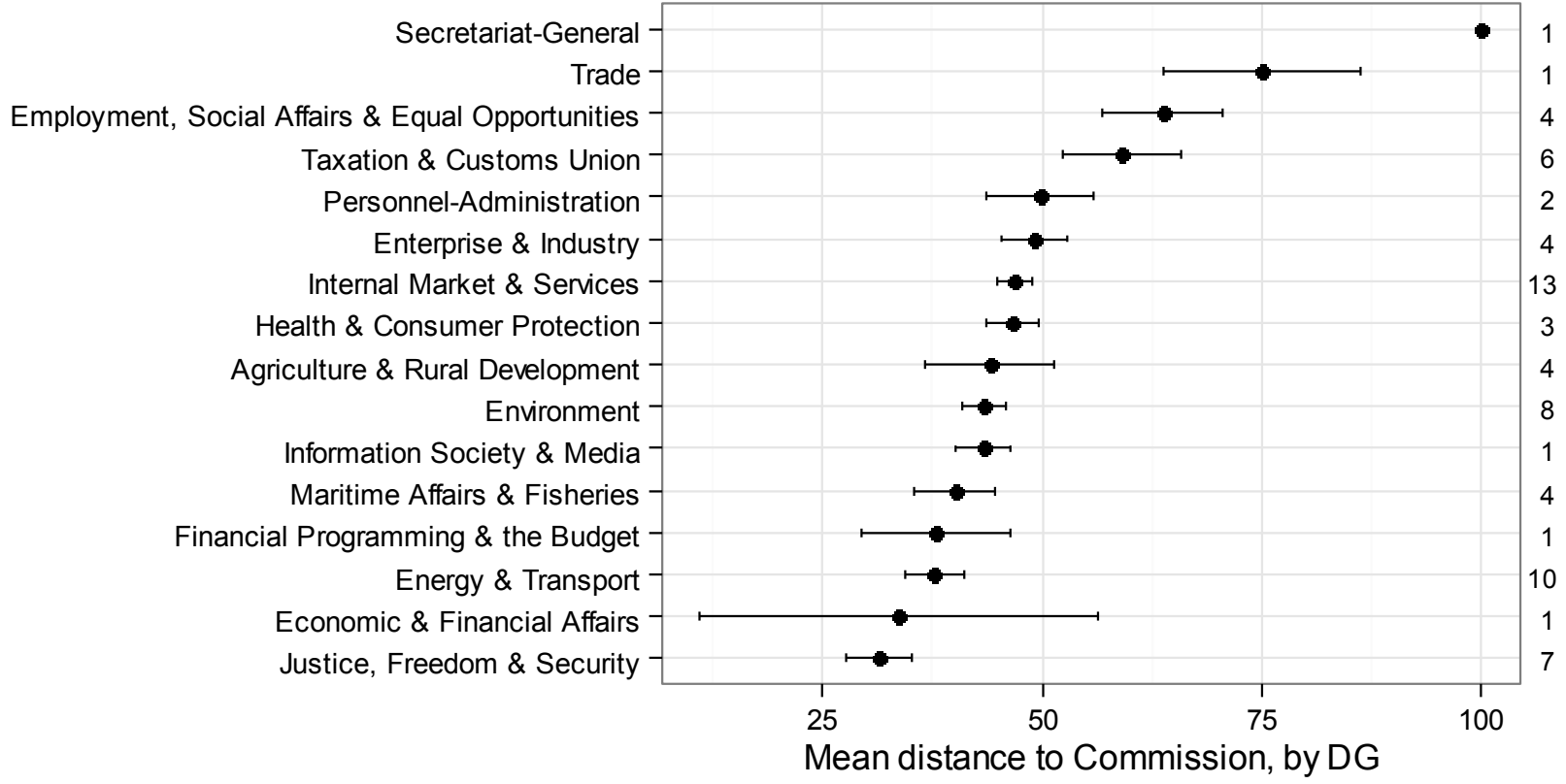

Note: the horizontal bars indicate the standard error of the mean. The numbers to the right refer to the number of proposals for each DG in our dataset.

Figure 2: Interaction of interest group knowledge and friendly DG

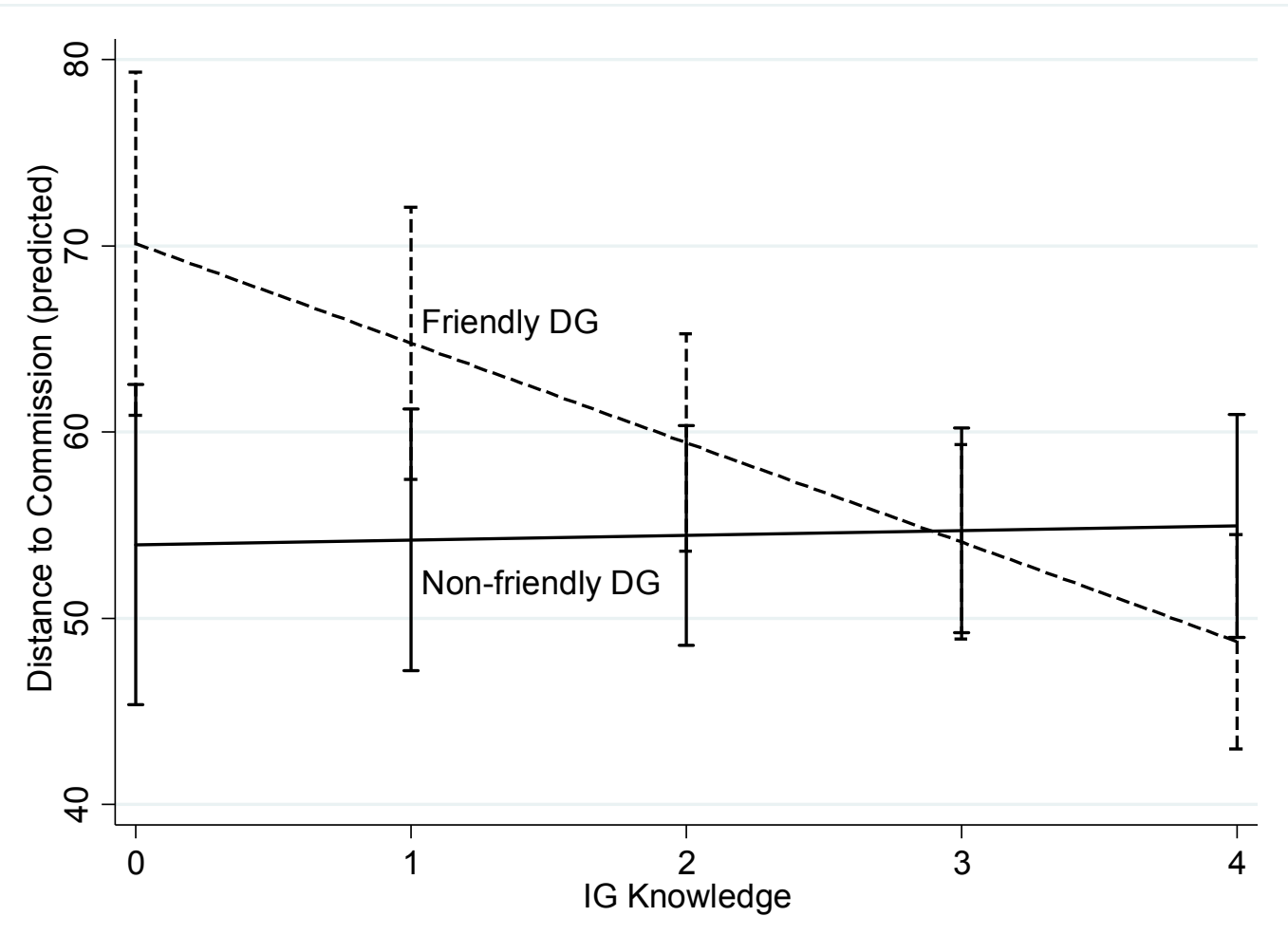

Note: Bars represent $90 \%$ confidence intervals. The predictions and confidence intervals are calculated while keeping other covariates at the mean and business at the mode. 
Figure 3: Interaction of interest group knowledge (side) and friendly DG (side)

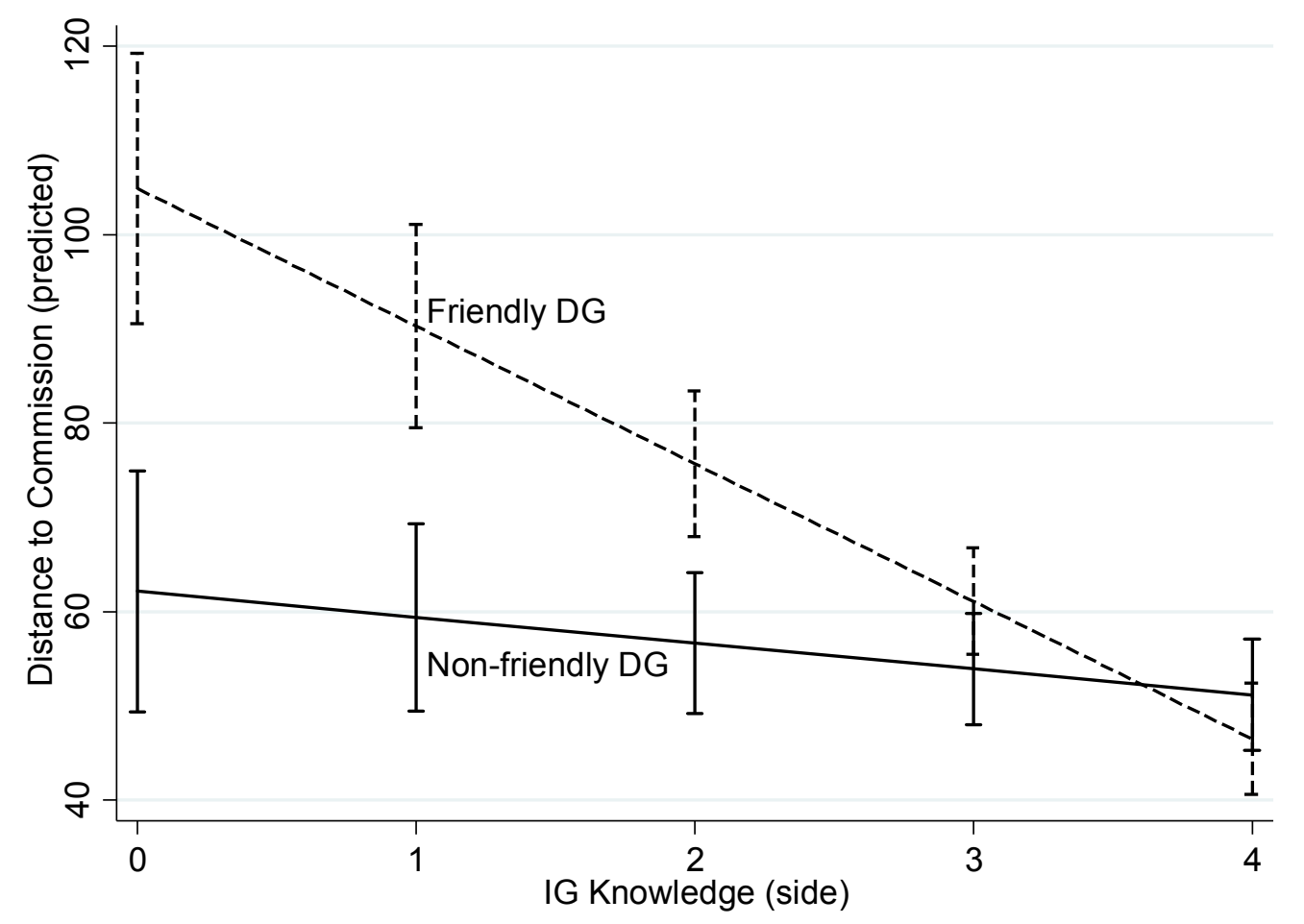

Note: Bars represent $90 \%$ confidence intervals. The predictions and confidence intervals are calculated while keeping other covariates at the mean and business at the mode.

Table 1: Multivariate regression models of Distance to Commission

\begin{tabular}{|c|c|c|c|c|}
\hline & $\begin{array}{l}\text { Model 1 } \\
\text { (individual) }\end{array}$ & $\begin{array}{l}\text { Model } 2 \\
\text { (side) }\end{array}$ & $\begin{array}{l}\text { Model 3 } \\
\text { (individual) }\end{array}$ & $\begin{array}{l}\text { Model } 4 \\
\text { (side) }\end{array}$ \\
\hline IG knowledge & $\begin{array}{c}-2.18^{* *} \\
(1.06)\end{array}$ & & $\begin{array}{c}0.25 \\
(1.36)\end{array}$ & \\
\hline Friendly DG & $\begin{array}{l}-1.40 \\
(2.86)\end{array}$ & & $\begin{array}{l}14.94^{* *} \\
(6.35)\end{array}$ & \\
\hline $\begin{array}{l}\text { IG knowledge * } \\
\text { Friendly DG }\end{array}$ & & & $\begin{array}{c}-5.59^{* * *} \\
(1.94)\end{array}$ & \\
\hline IG knowledge (side) & & $\begin{array}{c}-7.57^{* * *} \\
(1.58)\end{array}$ & & $\begin{array}{l}-2.76 \\
(2.00)\end{array}$ \\
\hline Friendly DG (side) & & $\begin{array}{c}2.62 \\
(3.22)\end{array}$ & & $\begin{array}{l}42.74^{* * * *} \\
(10.70)\end{array}$ \\
\hline $\begin{array}{l}\text { IG knowledge (side) } \\
{ }^{*} \text { Friendly DG (side }\end{array}$ & & & & $\begin{array}{c}-11.85^{* * *} \\
(3.02)\end{array}$ \\
\hline Regulation & $\begin{array}{l}9.45^{*} \\
(5.53)\end{array}$ & $\begin{array}{l}11.11^{* *} \\
(5.58)\end{array}$ & $\begin{array}{l}10.03^{*} \\
(5.63)\end{array}$ & $\begin{array}{c}12.43^{* *} \\
(5.84)\end{array}$ \\
\hline Side & $\begin{array}{l}1.74^{* * *} \\
(0.40)\end{array}$ & $\begin{array}{l}2.48^{* * *} \\
(0.41)\end{array}$ & $\begin{array}{l}1.82^{* * *} \\
(0.40)\end{array}$ & $\begin{array}{l}2.57^{* * *} \\
(0.41)\end{array}$ \\
\hline Media (logged) & $\begin{array}{c}0.66 \\
(3.09)\end{array}$ & $\begin{array}{c}0.48 \\
(3.12)\end{array}$ & $\begin{array}{c}0.80 \\
(3.14)\end{array}$ & $\begin{array}{c}0.87 \\
(3.26)\end{array}$ \\
\hline Business & $\begin{array}{c}15.62^{* * *} \\
(2.86)\end{array}$ & $\begin{array}{c}11.13^{* * *} \\
(2.45)\end{array}$ & $\begin{array}{c}16.16^{* * *} \\
(2.85)\end{array}$ & $\begin{array}{c}11.79^{* * *} \\
(2.44)\end{array}$ \\
\hline Intercept & $\begin{array}{c}29.84^{* * *} \\
(8.91)\end{array}$ & $\begin{array}{c}46.71^{* * *} \\
(9.68)\end{array}$ & $\begin{array}{l}21.56^{* *} \\
(9.46)\end{array}$ & $\begin{array}{l}27.81^{* *} \\
(11.06)\end{array}$ \\
\hline Observations & 929 & 985 & 929 & 985 \\
\hline
\end{tabular}


${ }^{1}$ Our definition of 'side' is similar to Klüver's (2013) concept of a 'coalition'. It differs from the similarly named concept of 'side' used by Baumgartner et al. (2009) because, unlike Baumgartner et al., we only include non-state actors in the set of actors making up a side. Our definition differs from the 'sides' used by Heinz et al. (1993) inasmuch as their sides are either for or against a legislative proposal, whereas in our analysis sides cover an interval of positions on a unidimensional issue space.

${ }^{2}$ For an overview of the project, see Beyers et al. 2014a.

${ }^{3}$ Beyers et al. (2014b) provide a more detailed discussion of the sampling process.

${ }^{4}$ Of the remaining proposals in the original sample, officials reported that no lobbying had taken place in 26 cases, and declined our requests for an interview in a further 29 instances. These cases were excluded from further analysis.

${ }^{5}$ Our definition of a policy issue thus corresponds to Baumgartner et al. (2009: 277), who took 'whatever the respondent described' as an issue. The challenges involved in interviewing policy experts are discussed in detail in (Beyers et al. (2014c).

${ }^{6}$ Some groups are counted several times as they lobbied on several issues. In total, we identified 501 unique actors.

${ }^{7}$ See Figure A-1 in the online appendix. Below, we name the DGs in accordance with the 2004-9 Commission (Barroso I), which encompasses the bulk of our observations. In 2010 both DG Justice, Freedom and Security and DG Energy and Transport were split in two. To facilitate comparability, we maintained the original coding. As the successor DGs would have been coded identically on their relation to the various interest groups, this does not affect our results in any way.

${ }^{8}$ Figure A-2 in the online appendix shows the distribution of distance to the Commission.

${ }^{9}$ Given this distinction between friendly and less friendly relations between interest groups and DGs, there is a possibility that Commission experts' rating of lobbyists' knowledge levels may be biased. However, the respective mean knowledge scores for groups defined in this way are hardly different: 3.07 for lobbyists acting in a friendly context and 2.91 others.

${ }^{10}$ In a small number of cases, consultations began during the 2009-2014 Commission (Barroso II). For the reasons outlined above in footnote 7, resulting changes to the identity of DGs make no difference to the coding outcome.

${ }^{11}$ Put differently, nearly two thirds of the business actors in our dataset face a friendly DG while only 14 per cent of other actors do.

${ }^{12}$ An explanation for this finding may be that groups with preferences far from the Commission's position may feel a particularly large need to engage in lobbying. 